\title{
La política exterior de Arabia Saudí: equilibrio entre factores domésticos y externos
}

\author{
Saudi Arabia's foreign policy: \\ Striking a balance between domestic and external factors
}

\begin{abstract}
ITXASO DOMÍNGUEZ DE OLAZÁBAL
\end{abstract}
Universidad Carlos III de Madrid

DAVID HERNÁNDEZ MARTÍNEZ

Universidad Autónoma de Madrid

\section{Cómo citar/Citation}

Domínguez de Olazábal, I. y Hernández Martínez, D. (2021). La política exterior de Arabia Saudí: equilibrio entre factores domésticos y externos. Revista Española de Ciencia Política, 56, 21-47. Doi: https://doi.org/10.21308/recp.56.01

\section{Resumen}

Este artículo analiza la evolución de la política exterior de Arabia Saudí, con un énfasis particular en la situación tras los levantamientos antiautoritarios de 2011. Con el marco teórico del realismo subalterno como punto de partida, el objeto de estudio se centra en cómo la estrecha vinculación entre la situación doméstica y los condicionantes externos, en particular en el contexto del Golfo y Oriente Próximo, ha orientado la forma en que la Corona ha articulado y desarrollado la estrategia exterior del país. El objetivo último del reino, ayer y hoy, consiste en garantizar la estabilidad de la Corona y otorgar legitimidad a su mandato. El artículo se centra en diferentes dimensiones de la llamada Doctrina Salman y en el destacado papel que en ella juega su hijo Mohammed bin Salman, príncipe heredero y actual ministro de Defensa, y repasa las principales cuestiones de la agenda nacional y regional del régimen saudí.

Palabras clave: Arabia Saudí, Oriente Próximo, política exterior, wahabismo, Primavera Árabe, realismo subalterno, Mohammed Ayoob.

\begin{abstract}
This article explores the evolution of Saudi Arabia's foreign policy, with a particular emphasis on the context following the 2011 anti-authoritarian uprisings. Drawing on the theoretical framework of subaltern realism, the study focuses on the close link between the country's domestic situation and external constraints, predominantly in the context of the Gulf and the so-called Middle East, and the way it has commanded the crown's articulation and implementation of the
\end{abstract}


country's foreign strategy. The kingdom's ultimate objective, both yesterday and today, is to guarantee the House of Saud's stability and legitimacy. The text pays special attention to the different dimensions of the so-called 'Salman doctrine' and the key role played by Crown Prince Mohammed bin Salman, currently Defense minister. It also reexamines the main issues on the Saudi regime's national and regional agenda.

Keywords: Saudi Arabia, Middle East, foreign policy, Wahhabism, Arab Spring, subaltern realism, Mohammed Ayoob.

There is nothing exceptional about Saudi Arabia. More nuanced research has explored the 'enigma' and reinserted the country into the regional history of the Arab world and beyond.

(Al-RAsheed, 2018: 26)

\section{INTRODUCCIÓN}

Arabia Saudí es actualmente uno de los Estados centrales de Oriente Próximo y de la esfera musulmana. Su relevancia estratégica reposa sobre una combinación de factores religiosos, culturales, políticos y económicos, integrados en una estrategia exterior diseñada a lo largo de décadas. El régimen no es ajeno a las transformaciones y nuevas realidades, tanto en su entorno como a escala internacional, que repercuten sobre la cohesión de la nación saudí. Estas nuevas vicisitudes obligan a la casa Saud a reconfigurar su estrategia regional e implementar reformas en el ámbito doméstico. El objetivo final es preservar la estabilidad interna y salvaguardar los intereses de la Corona saudí como potencia regional y aliado destacado de actores externos a la zona.

Las protestas antiautoritarias de 2011, conocidas como Primavera Árabe, supusieron un punto de inflexión en Oriente Próximo y norte de África: introdujeron profundos cambios y derivaron en elevados niveles de tensión. Esta coyuntura ha evolucionado hacia una sucesión de conflictos, crisis y rivalidades crecientes, en las que diferentes agentes intentan proteger o imponer sus propios objetivos. Este cúmulo de acontecimientos pone de relieve la estrecha vinculación entre situaciones domésticas, circunstancias regionales y contexto internacional. Los dirigentes saudíes se ven enfrentados a un período marcado por retos que cuestionaban su legitimidad, tanto en el interior de sus fronteras como en aquellas áreas que consideraban prioritarias.

El trabajo parte de dos preguntas de investigación centrales. En primer término, analiza cuáles son los principales elementos y factores domésticos y externos que condicionan la política exterior de Arabia Saudí desde el 2011 hasta 2020. En segundo lugar, valora cuáles son las interpretaciones de los contextos internos y externos, así como los objetivos y principios de los dirigentes saudíes, que guían la formulación e implementación de esta política exterior.

Este artículo analiza la política exterior de Arabia Saudí entre 2011 y 2020 desde una perspectiva multidimensional que tiene en cuenta tres procesos simultáneos y que 
se retroalimentan mutuamente. Por un lado, la situación interna y la necesidad dominante de la casa Saud de garantizar su supervivencia en el poder. Por otro, el panorama político de Oriente Próximo bajo un contexto de polarización y alianzas aparentemente antagónicas. En último término, la inferencia de las coyunturas abiertas en la comunidad internacional, sobre todo a través de las alianzas saudíes con potencias internacionales. El trabajo se inspira en la historia reciente del país para evidenciar que la estrategia exterior saudí se ve, tanto hoy como ayer, consecutivamente influida por necesidades domésticas. El texto pretende contextualizar cada acción y decisión del régimen en relación con los acontecimientos registrados dentro y fuera del reino.

La estructura del trabajo se divide en cinco partes. Tras la introducción, aparecen los aspectos teóricos y metodológicos de la investigación, con especial referencia al encuadre del realismo subalterno y el análisis de política exterior. En el apartado tres se realiza la exposición pormenorizada de los factores domésticos que influyen en la política exterior de Arabia Saudí. En el cuarto apartado se aborda la evolución de la acción regional del reino saudí tras la Primavera Árabe y las transformaciones en el entorno. En el epígrafe quinto se examina la estrategia seguida por el país árabe durante el reinado de Salman desde el 2015 y los objetivos de la llamada doctrina Salman. En la sección sexta se recogen las principales alianzas y rivalidades desarrolladas por Arabia Saudí en el contexto de Oriente Próximo. En el último apartado se presentan las conclusiones y reflexiones finales de la investigación.

\section{MARCO TEÓRICO Y METODOLOGÍA}

\section{Marco teórico}

La investigación se enmarca en el realismo subalterno, principalmente desarrollado por Mohamed Ayoob (2002), una de las primeras aproximaciones del pensamiento poscolonial a la teoría de las relaciones internacionales. El punto de partida lo representa el realismo clásico, con su énfasis en el Estado y la supervivencia de este como condicionante crítico de su acción exterior. El realismo subalterno cuestiona además el neorrealismo y el neoliberalismo, y considera que los factores centrales para entender dinámicas internacionales son el proceso de construcción del Estado y, en íntima relación con este, la construcción de comunidades políticas. En el realismo subalterno, la estrategia exterior de un país, muy particularmente la regional, está íntimamente vinculada con su condición de Estado poscolonial parte del Sur Global, con características y aspiraciones no siempre similares a los Estados del Norte Global. El texto parte de que este es todavía el caso de Arabia Saudí, a pesar de que algunos datos macroeconómicos e indicadores sociales pudieran indicar justamente lo contrario.

La construcción del Estado de Arabia Saudí, todavía en curso, representa una tarea doméstica con una dimensión externa, por lo que equilibrios regionales de poder favorables benefician al proceso (Ayoob, 1998: 43) y "las cuestiones de orden nacional y orden internacional están inextricablemente entrelazadas, especialmente en el ámbito 
del conflicto y la resolución de conflictos» (ibid.: 44). Ayoob pone particular énfasis en el concepto de conflicto doméstico, no necesariamente en referencia a la existencia de enfrentamientos corpóreos, sino a la vulnerabilidad del régimen a cargo de la construcción del Estado, celoso del mantenimiento de una cierta legitimidad que todavía reposa sobre cimientos inciertos, o al menos cuestionados. De acuerdo con dicho autor, los regímenes autoritarios utilizan la seguridad para subyugar a sus poblaciones, aunque con ello caen en una trampa de un continuum entre vulnerable y no vulnerable que también afecta a su legitimidad y les obliga a diseñar una narrativa securitizada en virtud de la cual elementos internos y externos representan amenazas al Estado (Ayoob, 1997: 130-131).

A diferencia de las vertientes realistas predominantes, desarrolladas en torno a países del Norte Global y basadas principalmente en la distribución del poder y la seguridad externa, el realismo subalterno parte de la importancia de las consideraciones domésticas para entender el surgimiento de conflictividad interestatal en distintas formas. Estos Estados, todavía en formación o consolidación —en el caso saudí, creado en 1932 - definen las amenazas a su seguridad y, en última instancia, a su supervivencia sobre la base de consideraciones externas e internas, conscientes de la sólida interconexión entre conflictos intraestatales e interestatales de diferentes intensidades, como consecuencia de fronteras trazadas por los poderes coloniales y la heterogeneidad étnica, religiosa y/o cultural (Ayoob, 2002: 38).

Los regímenes dedican importantes esfuerzos y recursos en sus relaciones con actores del entorno, especialmente donde perciben amenazas a su estabilidad (ibid.: 37). Esto no excluye su participación en dinámicas globales y búsqueda de aliados externos, siempre que refuercen la legitimidad del régimen. Por otro lado, estos Estados no persiguen, al contrario de lo que promulga la teoría neoliberal, intereses sociopolíticos o socioeconómicos; tampoco internacionales, sociopolíticos o económicos amplios e inclusivos más allá de salvaguardar los fines particularistas de las élites que construyen el país: por ejemplo, cuando se embarcan en procesos de integración regional, estos suelen ser con vistas a alcanzar exclusivamente objetivos nacionales.

Así, una de las amenazas críticas para la supervivencia del reino saudí se ve representada por aquellos elementos disruptivos - internos y externos- que cuestionan la legitimidad y estabilidad del régimen (Gause, 2003: 303). Los diferentes monarcas saudíes han perseguido la seguridad externa tomando en consideración objetivos de equilibrio doméstico (Nonneman, 2005: 318). Este marco ayuda a entender en profundidad que las sucesivas estrategias de política exterior de Arabia Saudí deben sopesar y explicar, al mismo tiempo y con el mismo peso, dinámicas externas e internas.

\section{Metodología}

El marco de análisis del estudio es el definido por la política exterior (Azaola, 2019), que establece una diferencia entre tres niveles de observación para evaluar el comportamiento de un Estado en las relaciones internacionales: el global, el regional/ 
subregional y el nacional. Además, en relación con la esfera doméstica saudí se hace necesario considerar la estrecha interrelación que existe entre las decisiones del monarca y las políticas del reino en un país donde la personalización y la patrimonialización del Estado caracterizan todo el proceso de toma de decisiones (Médard, 1990; Mouline, 2010; Hinnebusch, 2003: 110-120; Mabon, 2018: 3).

\section{LA DIMENSIÓN DOMÉSTICA EN LA ARTICULACIÓN DE LA POLÍTICA EXTERIOR SAUDÍ}

Desde la creación del Estado moderno saudí en 1932, el objetivo fundamental fue construir un nuevo país y mantener a los Saud en el poder, en una imbricación constante entre Corona, religión y nación. La configuración del reino se desarrolla según los objetivos del clan familiar. Los saudíes se encargaron de dotar inicialmente al régimen de un sentido político patrimonial, donde los recursos y todos los espacios de poder son copados por el rey y su familia (Charrad, 2011: 51-52). El resultado es que el Estado opera según una política nacional e internacional marcada directamente por las premisas del monarca y su círculo de mayor confianza. Los intereses nacionales no se distinguen de los fines e intereses de la dinastía real, rigiéndose la acción exterior según las apreciaciones de oportunidades y amenazas que existen para la monarquía.

El carácter patrimonial del régimen se produce por la extrema preocupación de la casa Saud por controlar todos los ámbitos políticos y sociales del Estado en construcción, lo que proporciona una elevada concentración de poder en la figura del rey. La estabilidad y seguridad representan dos elementos centrales de la política del reino. Arabia Saudí actúa como una potencia dentro del complejo de contexto regional multipolar de Oriente Próximo: las distintas acciones y decisiones y, por encima de todo, las líneas estratégicas se ven moldeadas por la percepción de amenazas a su seguridad y estabilidad en distintas formas y con distintos orígenes (Buzan y Waever, 2003; Chalk, 2004).

Los dirigentes saudíes comprenden que su porvenir político queda determinado tanto por las dinámicas domésticas como por lo que pueda ocurrir en su entorno. Un principio irrenunciable de la política exterior está en salvaguardar una posición de liderazgo en la región, el único mecanismo que les permite una cierta certidumbre ante fuerzas divergentes. El objetivo de mantener una posición predominante obligaba a perseguir activamente una cierta estabilidad que evite convulsiones o focos de conflicto en la región, que puedan derivar en tensiones y divisiones sociales dentro del reino. Se lograba asimismo garantizar el sosiego que representa para un Estado rentista el maná de la economía política de los hidrocarburos. En última instancia, también se conseguía conservar intacta la alianza con Estados Unidos, para la que Riad jugaba el rol de mediador privilegiado en un vecindario turbulento (Kamrava, 2013).

El primer ejemplo de reacción preventiva ante amenazas externas fue el sólido posicionamiento de Riad en la primera guerra fría regional entre regímenes republicanos y monárquicos en la década de los sesenta del pasado siglo, al mismo tiempo que 
la Corona hacía frente a numerosos focos de oposición internos (Al-Rasheed, 2010: 103 , 124). Otro caso destacable fue la primera guerra del Golfo en 1991, en particular la perturbación en el país por la presencia de tropas estadounidenses desplegadas en el territorio (ibid: : 171). La tercera evidencia surgió en el contexto posterior a los ataques terroristas del 11 de septiembre de 2001. El reino quedó en una situación delicada en el ámbito internacional, con una reputación y vínculo con Occidente marcadamente deteriorados, mientras que en el ámbito interno una campaña de terror se vio intensificada con la invasión de Irak en 2003 (ibid.: 233).

Son tres los mecanismos de los que Arabia Saudí se sirve primordialmente para su estrategia exterior, que arrojan luz sobre la fuerte relación que existe entre la dimensión externa y la dimensión interna: uno es la religión; otro el llamado «regionalismo regime-boosting», ambos considerados mecanismos de soft power (Gallarotti y Al-Filali, 2012), y un tercero son los hidrocarburos.

En lo que a la religión respecta, la alianza centenaria entre los Saud y el wahabismo, y la presencia de los dos lugares sagrados para el islam en territorio saudí, han permitido al régimen saudí servirse del islam para legitimar decisiones ante sus nacionales ejercer cierta influencia en gran parte del mundo árabe y musulmán. El papel de liderazgo que pretende protagonizar Arabia Saudí en todo Oriente Próximo y demás áreas con presencia del islam se justifica recurriendo a la cosmovisión wahabita que impregna la acción internacional de una retórica excepcionalista (Ottaway, 2011: 3-4). Los axiomas del wahabismo se erigen en cimientos de un panorama religioso y político en el que la casa Saud actúa como guía y defensor de la auténtica fe.

A partir de las décadas de 1950 y 1960, y en el marco de la guerra fría entre republicanos y monárquicos, el rey Faisal promovió la religión como ideología alternativa al nacionalismo árabe. En 1979, la revolución en Irán y el secuestro de la Gran Mezquita de la Meca, junto a una inestabilidad creciente en la Provincia Oriental, se perfilaron como amenazas significativas a la legitimidad doméstica e internacional del régimen. Esta época se erige como punto de inflexión para el refuerzo del liderazgo regional y las credenciales islámicas saudíes (Ahrari, 1989). El recurso a la religión explica el significativo papel que han jugado los ulemas en la política exterior, tanto en la arena propagandística interior como en actividades de proselitismo (da'wa) a lo largo de las últimas décadas (Hammond, 2018).

La creación de la Liga Mundial Musulmana (1962) y de la Organización para la Conferencia Islámica (1967) representan ejemplos de la instrumentalización de la religión y del llamado «regionalismo regime-boosting». El régimen saudí busca fortalecer su estatus y legitimidad, tanto en el ámbito internacional como a nivel nacional, sirviéndose de instituciones regionales (Söderbaum, 2010: 6). Arabia Saudí es miembro de un entramado de organizaciones internacionales, donde la prioridad es convertirlos en escenarios donde reafirmar su soberanía y liderazgo, utilizándolos como plataformas propagandísticas ante los ciudadanos y el resto de la comunidad internacional, y también como foros donde visibilizar diferencias discursivas entre países (ibid:: 8; Chabal y Daloz, 1999; Söderbaum, 2001: 192). 
En este sentido, las rentas obtenidas de los hidrocarburos sirven de soporte financiero para las grandes iniciativas internacionales, así como importantes inversiones en el sector de la defensa para reforzar sus capacidades militares. Al mismo tiempo, gracias a las rentas del petróleo, la casa Saud cumple el contrato social sui generis que aún mantiene con sus súbditos (Campbell y Yetiv, 2017), siguiendo los principios de modelos rentistas neopatrimoniales, que redistribuyen los recursos de acuerdo con redes patrón-cliente (Bewlavi, 1990). Sin embargo, la aplicación de la teoría del Estado rentista en el caso de Arabia Saudí debe ser matizada en atención a su economía política, en la que los hidrocarburos son centrales y han sido explotados de acuerdo con principios capitalistas en procesos eminentemente globales de internacionalización de capital, a través de instrumentos como conglomerados activos en una variedad de sectores económicos controlados por familias estrechamente vinculadas con la familia gobernante y las estructuras estatales, lo que ha contribuido al éxito de la acumulación de capital (Hanieh, 2011).

\section{EL RÉGIMEN SAUDÍ ANTE LA PRIMAVERA ÁRABE}

\section{Arabia Saudi frente a los cambios en el contexto regional}

Las movilizaciones que se extendieron por numerosos países árabes representaron una doble brecha en el statu quo de los diferentes contextos domésticos y de la situación regional en su conjunto. Por un lado, evidenciaron la gran grieta concurrente entre las poblaciones y las clases dirigentes. Por otro, revitalizaron la fractura ideológica e intereses entre regímenes, propiciando un aumento de incertidumbre e inseguridad. La inestabilidad en diferentes puntos de la zona abocó a que distintos actores estatales plantearan cambios profundos en sus estrategias. Riad fue un ejemplo destacado.

Arabia Saudí actuó durante este período bajo una lógica contrarrevolucionaria, que intentó liderar el bloque que refrenaba corrientes de cambio. Los esfuerzos de la monarquía se focalizaron en reducir las posibilidades de movimientos de contestación dentro del reino (Gause, 2011: 7-9), al mismo tiempo que buscaban adaptar sus respuestas a los complejos acontecimientos regionales. Las diferentes crisis en el entorno afectaron notablemente a los intereses de la monarquía. Arabia Saudí se encontró en una posición más frágil que antes de que estallaran las protestas de 2011, obligada a hacer frente a numerosos desafíos y diferentes resistencias a su estatus preeminente (Dalacoura, 2012: 77-78). El Estado saudí inició una fase de redefinición de su forma de intervención en el entorno para preservar sus intereses.

La percepción entre los dirigentes saudíes era que la inestabilidad ayudó a mejorar la posición de sus competidores en la región. El régimen wahabita encaró importantes obstáculos a la hora de implementar una agenda regional que le permitiera continuar siendo el punto referencial (Al Tamamy, 2012: 154). Sus preocupaciones están en la evolución de los conflictos de Yemen y Siria, así como las dinámicas internas en el Líbano, Egipto o Irak. No obstante, los riesgos más excepcionales los representaban 
el protagonismo creciente de Irán y las divisiones en el seno del Consejo de Cooperación del Golfo (CCG), muy particularmente la rivalidad creciente con Qatar.

Las diferentes crisis regionales supusieron un doble desafío para el liderazgo de Arabia Saudí, que explica su faceta de elemento contrarrevolucionario y, al mismo tiempo, propulsor de nuevos actores en terceros países, como su apoyo a milicias rebeldes en Siria (Mabon, 2016: 180-185). En términos generales, la presencia creciente de movimientos contestatarios en el entorno es percibidos por los Saud como una amenaza directa a su modelo político. Riad se vio abocada a ayudar a aquellos regímenes afines, mientras respaldaba a facciones opositoras y rebeldes con las que compartía unos objetivos similares, todo ello con el propósito de contrarrestar tanto la influencia iraní como agendas programáticas alternativas a las de Arabia Saudí.

La preocupación de la casa Saud por proteger a otras dinastías reales se extiende más allá de los contornos del Golfo. Jordania y Marruecos son dos casos destacados de la acción saudí a escala regional e internacional en torno a la esfera musulmana. El apoyo y protección a estos regímenes deviene de un doble interés: en primer término, salvaguardar la monarquía como el modelo político idóneo para la zona, defendiendo la "excepcionalidad monárquica» frente los profundos cambios en el entorno (Yom y Gause, 2012: 76-78) En segundo lugar, ampliar los márgenes de influencia de Arabia Saudí, consolidando sus relaciones con aquellos dirigentes con los que comparte cierta proximidad de intereses y que podrían formar parte del eje suní promovido desde Riad.

En la respuesta saudí a los cambios regionales destacan dos etapas, que muestran visiones distintas dentro de la casa Saud sobre la forma de abordar la complicada realidad política. En primer término, la gestión realizada por el rey Abdalá se caracterizó por una línea centrada en preservar la estabilidad interna y de bajo perfil exterior. En contraposición, a partir de 2015, el rey Salman y el príncipe heredero Mohammed bin Salman (conocido por su acrónimo MbS) introdujeron una estrategia que sigue una línea de acción más proactiva en el escenario doméstico e internacional.

El rey Abdalá hizo frente a los cambios en la región desde una visión cautelosa y comedida, bajo el principio de aislar al reino de las posibles coyunturas de cambio emergentes (Steinberg, 2014: 15-16). Esta decisión permitió al régimen saudí controlar y reducir el alcance de las transformaciones dentro del reino, superando los instantes de mayor virulencia de las reivindicaciones. No obstante, la percepción desde algunos círculos de poder de Riad fue que los años en los que se priorizó la agenda nacional incidieron negativamente en el papel de Arabia Saudí en las principales crisis regionales, alentando la ascensión de otros bloques y agentes competidores.

A pesar de diferencias especificadas, los monarcas Abdalá y Salman muestran continuidad en priorizar determinados apoyos en el entorno. La respuesta saudí a los cambios regionales consistió en respaldar decididamente a sus aliados: el caso de las intervenciones militares en Bahréin en 2011 y en Yemen a partir de 2015, o bien de las ayudas económicas al régimen egipcio de Abdel Fattah Al Sisi tras el golpe de Estado contra el presidente Mohammed Morsi en 2013. Siria representó el único espacio de Oriente Próximo en el que los saudíes se decantaron por respaldar a facciones opositoras para intentar reducir la influencia iraní. 


\section{El impacto de las protestas en el orden interno}

El régimen saudí tenía que actuar ante los diversos acontecimientos tras las revueltas de 2011, consciente del riesgo de contagio en su territorio (Kamrava, 2011: 99). Los objetivos fundamentales eran prevenir el caos (fitna) en los regímenes aliados y defender la legitimidad de la monarquía como sistema de gobierno en el mundo árabe. Aunque no existía una sociedad civil consolidada en Arabia Saudí, consecuencia de amplios mecanismos de represión, surgieron brotes de insatisfacción que el régimen logró contener gracias a una meditada combinación de coerción y dádivas (Al-Rasheed, 2015a). El argumento aducido fue que los conflictos del entorno representaban una seria amenaza para la propia cohesión territorial y supervivencia del país.

Sin embargo, entre los diferentes tipos de contestación interna al poder de los Saud pueden destacarse por su incidencia histórica las reivindicaciones de la población chií del este del país y las diversas corrientes y plataformas dentro del islam político en el reino.

\section{El dilema de la Provincia Oriental}

Gran parte de la atención del régimen en 2011 se focalizó en la Provincia Oriental, una zona de enorme valor estratégico en la que reside una significativa minoría chií. Esta parte de la población saudí ha sido durante décadas discriminada por su condición religiosa, lo que derivó en un conflicto interno que nada tenía de sectario en un primer momento (Matthiesen, 2014). El régimen se sirvió de esta colisión para erigir a la comunidad chií en chivo expiatorio, ya que actuarían supuestamente influenciados por Irán (Al-Rasheed, 2017: 150). Las autoridades saudíes acusaban a Teherán de tratar de sembrar el caos dentro del reino, y ponían como ejemplo las movilizaciones ocurridas en Baréin en los primeros meses de 2011 (Matthiesen, 2012: 658).

El marco de amenaza iraní utilizado por Riad para justificar ante el resto de sus súbditos la represión en la Provincia Oriental (aunque también se puso en marcha una estrategia de palo y zanahoria) sirvió para deslegitimar las razones - compartidas por un importante número de saudíes - que habían llevado a diversas microrrevueltas $\mathrm{y}$, por lo tanto, pacificar también a aquellos ciudadanos que habían sido protagonistas en su descontento (Al-Rasheed, 2014: 357). Con la intervención militar de la Fuerza Escudo del Consejo de Cooperación del Golfo en Bahréin, Arabia Saudí dejó claro que no permitiría ningún tipo de desestabilización en el ámbito regional (Ulrichsen, 2014).

En enero de 2016, la ejecución del jeque chií Nimr Baqir al-Nimr, líder de las protestas de 2011, representó la interrelación entre consideraciones domésticas y externas y la instrumentación política de las divisiones sectarias (Alamer, 2016). Un importante número de ciudadanos suníes aplaudieron la decisión: según el wahabismo oficial, el clérigo chií representaba una herejía religiosa y política (Gengler, 2017). La reacción externa implicó tanto severas condenas por parte de Occidente 
como una escalada de tensiones con Irán. La ejecución tuvo lugar en un momento en el que la Corona saudí necesitaba desviar la atención de la trayectoria desfavorable de la guerra en Yemen y de algunas medidas fiscales y económicas controvertidas.

\section{La «amenaza» del islam politico}

El régimen saudí ha recurrido a la religión como fuente de legitimidad para promover los intereses del Estado, en oposición a reivindicaciones foráneas de influencia islámica y regional (Halliday, 2005: 218). No obstante, este liderazgo religioso también puede representar en ocasiones una debilidad para los gobernantes saudíes, ya que implica una serie de limitaciones en el proceso de adopción de determinadas estrategias, así como un punto de crítica a la que se atienen sus rivales (Gause, 2003; Nuruzzaman, 2017).

La relación especial entre los Saud y el wahabismo no siempre ha impedido que algunos actores cuestionen las credenciales islámicas del régimen, acusándolo de haber traicionado los fundamentos del movimiento wahabita del siglo XviII. Estas críticas al régimen ponen en peligro la estabilidad interna, además de debilitar de las relaciones entre la monarquía y varios de sus aliados extranjeros. La necesidad de erradicar estos grupos sobre el terreno y cercenar sus capacidades financieras se han convertido en uno de los pilares centrales de la estrategia de seguridad planteada por MbS.

La existencia del Dáesh (las siglas en árabes del Estado Islámico en Iraq y el Levante) constituye una amenaza para la estabilidad doméstica: algunos islamistas saudíes mostraron simpatía hacia el discurso antichií de la formación y se perpetraron diversos ataques terroristas entre 2014 y 2016. La situación es también peligrosa para la imagen exterior de Arabia Saudí. Sin embargo, las acciones yihadistas parecieron fortalecer la narrativa del régimen, apoyada por la creación de una coalición internacional contra el terrorismo, con la cual el Estado saudí se presenta como una víctima y no uno de los espacios de apoyo a grupos radicales (Al-Rasheed, 2018: 15).

La complicada relación entre Arabia Saudí y los movimientos islamistas es otra importante dimensión que enlaza la estrategia doméstica y exterior de instrumentalización del islam como vector discursivo de legitimidad. Arabia Saudí, de hecho, no siempre ha visto a los Hermanos Musulmanes como una amenaza regional, sino que en ocasiones se sirvió de ella para contrarrestar la popularidad del panarabismo y el comunismo, además de para construir el Estado moderno gracias a profesores e ingenieros egipcios, que encontraron refugio en territorio saudí.

El auge del movimiento al-sahwa al-islamiyya (en árabe, despertar islámico) o simplemente Sahwa, representó una fase de considerables cambios, impulsados por representantes de la Hermandad en la década de los sesenta, aunque posteriormente terminara desligándose de dicha organización. La tensión entre el régimen y la corriente islamista surgió a partir de la invitación de Arabia Saudí al despliegue de tropas extranjeras con ocasión de la guerra del Golfo en 1991. Sahwa lanzó una campaña nacional en contra de la decisión, formulando una serie de demandas 
sociopolíticas. Estas actitudes fueron duramente reprimidas y se intensificaron tras los ataques terroristas del $11 \mathrm{~S}$, asociándolo a la una campańa mundial contra el terrorismo.

Los impulsores e ideólogos de Sahwa, en particular Salman al-Awda, vieron en los levantamientos de 2011 una oportunidad renovada para exigir reformas políticas. El régimen saudí volvió a considerar a los Hermanos Musulmanes como una seria amenaza, tanto dentro como fuera de sus fronteras. Ese fue el caso de Egipto, donde los líderes saudíes no podían tolerar una alternativa de democracia de inspiración islámica. Arabia Saudí apoyó el golpe de Estado que derrocó a Mohammed Morsi en julio de 2013 (Al-Rasheed, 2014: 373), y en 2014 designó a la Hermandad como organización terrorista, iniciando una campańa de persecución contra la organización a escala regional.

La sucesión del rey Abdullah por el rey Salman dio lugar a una cierta distensión con el movimiento islamista. En 2015, el reino recibió a varios líderes vinculados a la cofradía: Rachid Ghannouchi, del partido tunecino Ennahda; Abdula Majeed Zindani, de la formación yemení al Islah, o Khaled Meshaal, exlíder de Hamás. Sin embargo, la distensión con estos grupos políticos fue limitada. El príncipe MbS retomó medidas represivas en el interior del país contra religiosos adscritos a Sahwa. En el extranjero, puso en marcha una campaña junto con Emiratos Árabes Unidos en contra de la influencia creciente de tendencias islamistas en Oriente de Próximo, Norte de África o el Sahel. De hecho, la crisis con Qatar tiene entre sus principales causas los vínculos de la dinastía $\mathrm{Al}$ Thani con diferentes polos islamistas en la región.

\section{CAMBIOS Y CONTRADICCIONES EN EL REINADO DE SALMAN}

\section{La Doctrina Salman en la politica saudi para Oriente Próximo}

La llegada al poder del rey Salman conllevó notables cambios institucionales en Arabia Saudí. El componente más destacado fue la acumulación de poder del príncipe heredero Mohammed bin Salman. Una de sus grandes apuestas fue implementar un enfoque más proactivo y multidimensional en política exterior. El príncipe parece muy consciente de los peligros a los que se enfrenta el proceso de construcción estatal todavía sin consolidar del país (Ayoob, 2002), y en este sentido ha dirigido sus esfuerzos tanto a sofocar conflictos domésticos como a servirse de conflictos regionales para reforzar la legitimidad del régimen. Abandona, así, el enfoque de Abdalá que consideraba insuficiente, priorizando la presencia saudí creciente y simultánea en varios escenarios.

La doctrina Salman abarca la totalidad de la política exterior saudí, aunque su centro de acción está en Oriente Próximo. Sin embargo, el reino busca fortalecer alianzas no solo en el entorno cercano, sino también en otras áreas de influencia musulmana como el Magreb, África Subsahariana, Asia Central y la cuenca del Pacífico. La nueva estrategia saudí contó con el respaldo de la Administración Trump, que 
intentó vertebrar un eje con la mayoría de las monarquías árabes y el Estado de Israel para hacer frente a la amenaza iraní (Ahmadian, 2018: 141-143). La complementariedad con las tesis del presidente Donald Trump motivan que el régimen wahabita se sienta menos presionado que durante la presidencia de Barack Obama.

La política exterior saudí reciente ha estado condicionada por la brecha de confianza entre la Administración estadounidense y la casa Saud. La estrategia para Oriente Próximo de Barack Obama estuvo condicionada por el interés de pivotar hacia Asia (Krieg, 2016: 105-107), disminuyendo las acciones en este entorno a pesar de la Primavera Árabe. El apoyo limitado a regímenes aliados y el diálogo con Irán provocó un intenso malestar entre los dirigentes saudíes. La histórica alianza quedó gravemente erosionada, evidenciándose la disparidad de intereses entre las partes. La decisión de Donald Trump de enmendar sustancialmente la política de su predecesor supone un reencuentro con las tesis saudíes y la perspectiva adoptada por MbS.

Bajo esta doctrina, Riad también se desvincula de algunos aspectos de su política exterior que representa más inconvenientes que beneficios, como es la causa palestina. A lo largo de las décadas, consciente de su potencial utilitario para erigirse como mediador y líder regional y su peso simbólico en el mundo árabe, la casa Saud mantuvo cierto compromiso con la cuestión palestina. Sin embargo, este interés político no le ha impedido reforzar progresivamente sus relaciones con Israel en numerosos ámbitos y siempre de forma no oficial, reforzado por percepciones de amenazas compartidas, como la actitud de Irán o el contexto post-2011.

La aproximación con la Administración de Donald Trump no impidió que desde Arabia Saudí se continuara fortaleciendo los vínculos políticos y económicos con otras potencias internacionales, debido al interés de la Corona saudí por diversificar sus relaciones en el escenario mundial. La relación con China se remonta a finales de la década de los ochenta del pasado siglo, aunque ha aumentado exponencialmente a lo largo del siglo XXI, acorde con la creciente presencia del régimen comunista en puntos clave de Oriente Medio. La asociación entre Pekín y Riad se vertebra principalmente sobre aspectos comerciales y sectores energéticos (Gater-Smith, 2018: 94-95), aunque también se abordan otras cuestiones como acuerdos de armamento y equipos militares.

Rusia es la potencia internacional que ha tenido unas relaciones más distantes con Arabia Saudí en las últimas décadas. El interés saudí por apoyar a determinadas facciones y grupos islamistas en las regiones del Cáucaso y Asia Central interfiere con los objetivos securitarios de Moscú. Sin embargo, el papel protagonista que está adquiriendo el Kremlin en algunas de las principales crisis de Oriente Medio, como la guerra en Siria, está motivando un acercamiento sin precedentes entre la casa Saud y el Gobierno de Vladimir Putin. Ambos regímenes buscan espacios de cooperación política para atender los grandes problemas regionales, reduciendo las tensiones y discrepancias entre los dos países, mientras impulsan los intercambios e inversiones comerciales.

Arabia Saudí ha reactivado su presencia en aquellos puntos que considera críticos para la estabilidad de la región y para consolidar su posición de liderazgo. El propósito de la estrategia consiste en no perder espacios de influencia en el entorno y, al mismo 
tiempo, contrarrestar el ascenso de otras potencias y, sobre todo, hacer frente al Estado iraní. Esta apreciación de circunstancias actuales conduce a la Corona saudí a aumentar su rol en escenarios tan diversos como Líbano, Irak, Yemen o Siria, en los que la debilidad de los respectivos regímenes le permite salvaguardar sus intereses.

El mecanismo preferente es el apoyo político y económico a aquellos actores con los que la Corona saudí tiene una mayor afinidad ideológica. La canalización de este tipo de asociación se da en relación directa con regímenes, como Bahréin o Egipto, o bien con agentes con presencia política y religiosa en las disputas internas de sus países, como el movimiento suní Al-Hal en Irak o el partido de Saad Hariri, Tayyar Al-Mustaqbal, en el Líbano. El Estado saudí se convierte en el gran valedor internacional de facciones suníes en diferentes franjas de Oriente Próximo (Jayamaha et al., 2019), con lo que busca contrarrestar la presencia del eje iraní y seguir siendo un actor decisivo en los principales escenarios de la agenda regional.

El otro componente destacado de la doctrina Salman lo representa la variedad de recursos utilizados para alcanzar sus objetivos. Arabia Saudí optó en el pasado por recurrir a mecanismos de índole cultural, diplomático y económico. Esta nueva fase se ve caracterizada por la militarización de su acción exterior (Nuruzzaman, 2019: 43-45). Las Fuerzas Armadas dejan de tener un carácter puramente defensivo y vinculado al orden interno, y son desplegadas en territorios extranjeros para defender los intereses del reino. La finalidad es convertirlas en una herramienta útil para garantizar su preponderancia en el vecindario y, en este sentido, la estabilidad en países aliados.

La nueva estrategia del príncipe MbS destaca por su carácter ofensivo y proactivo. En el pasado, la casa Saud buscó construir un multilateralismo eficaz en Oriente Próximo y en la esfera musulmana, donde Riad figurara como principal protagonista, pero siempre bajo el consenso con los demás regímenes. Sin embargo, la actual doctrina ejerce una autoridad más beligerante y coercitiva, que no aspira a grandes espacios de conformidad, sino establecer una fuerte polarización regional entre lo que considera su bloque y las potencias ajenas al mismo.

\section{La figura de MbS en la politica nacional del reino}

a) Saudi Vision 2030 y el sindrome McKinsey

El boom del petróleo en 2003 prorrogó la necesidad de hacer frente a los desafíos internos. Sin embargo, los levantamientos antiautoritarios de 2011 pusieron de manifiesto los paralelismos entre los desequilibrios socioeconómicos en otros países y en el reino. El recurso del palo y la zanahoria no era sostenible en el medio plazo. El régimen saudí siguió el esquema de sus vecinos en el Golfo, con una estrategia de modernización elaborada por consultoras extranjeras. En 2016, MbS presentó Saudi Visión 2030, que planteaba hacer frente al déficit presupuestario y reducir el gasto público, la diversificación económica, saudización del empleo y privatización del sector productivo, además de otras iniciativas educativas (Al-Kibsi et al., 2015). 
Estos proyectos de modernización no representan el paso a una economía globalizada de una economía previamente cerrada, sino que se replican las líneas maestras de la estrategia saudí en el plano económico internacional a lo largo de décadas, basada en un proceso de acumulación e internacionalización de capital, de acuerdo con políticas económicas neoliberales centradas en el mercado, que buscan convertir el CCG en un núcleo tanto regional como internacional (Hanieh, 2011). No obstante, las líneas de actuación planteadas por la Corona saudí no repercuten seriamente en la naturaleza neopatrimonial de su modelo político y económico. Un sistema aún predominante en la región (Bank y Richter, 2010: 6-8), marcado por una fuerte naturaleza rentista y clientelar, con una limitada participación política y preservando los mecanismos de concentración de poder en torno al rey y a una élite nacional. Las reformas introducidas van encaminadas a preservar esos elementos de poder estructurales, mientras modifican solamente los aspectos que permitan a la economía saudí competir y destacar en el entorno y en el contexto mundial.

Saudi Vision 2030 no es realmente una medida novedosa dentro del régimen de Arabia Saudí, ya que a lo largo de la breve historia del Estado saudí se han ido introduciendo reformas, principalmente en materia económica, para asegurar la pervivencia de su particular modelo autoritario. La monarquía de los Saud pasó progresivamente de un sistema patrimonial a uno de carácter neopatrimonial, por medio de lo cual se ha logrado establecer instituciones y Administraciones burocráticas propias de un Estado moderno (Bach, 2011: 276-278), mientras se mantiene la autoridad incuestionable del rey, el estatus privilegiado de la familia real y su presencia dominante en todas las esferas políticas y sociales de responsabilidad, así como un predominio de relaciones de poder basado en lealtades personales y redes clientelares.

Las reformas no intentan romper con estas dinámicas estructurales, sino modificar los aspectos más frágiles del régimen. Saudi Vision 2030 presenta una estrategia de modernización centrada en la arena doméstica, al tratar de aplacar el conflicto intraestatal. Una primera arista la constituye la necesidad de transparencia y un menor rol del Estado, algo que no parece fácil en Arabia Saudí. Por un lado, el régimen muestra inquietud por permitir que la sociedad internacional conozca las complejidades del régimen. Por otro, un menor protagonismo del Estado podría inducir la reversión de procesos de nacionalización, menor margen de la familia real y mayor apertura política. Sin embargo, la economía política saudí de las últimas décadas evidencia que el alineamiento con las tendencias globales en el ámbito financiero y macroeconómico tendría como objetivo final afianzar el modelo de Estado rentista neopatrimonial autoritario, no un posible desmantelamiento progresivo (Baumann, 2019).

También resulta interesante el ejemplo de Neom, una ciudad ultramoderna en construcción al norte del país, entre Arabia Saudí, Egipto y Jordania, en la que el reino tendrá todas las competencias en materia de defensa y seguridad como ejemplo de su comportamiento regional (Mabon, 2018). La diversificación económica que encomienda Saudi Visión 2030 también se vería acompañada por la proliferación de aliados en el plano económico y comercial, en particular en lo referido al continente 
asiático, tanto en países de mayoría musulmana como en países no musulmanes, como China y Japón.

Saudi Visión 2030 aspira a la creación de un Estado sostenible posdependencia del petróleo. No obstante, los hidrocarburos siguen siendo claves para el régimen, tanto para cumplir con su parte del contrato social como para financiar su política exterior. A finales de 2014, Arabia Saudí bloqueó las exigencias de miembros de la OPEP de recortar la producción para detener la caída de los precios mundiales. Su objetivo consistía en conservar su cuota de mercado e, incluso, con este fin articuló a finales de 2016 con Rusia el conocido grupo OPEP+ con el fin de mantener artificialmente elevados los precios del petróleo. En el momento de redacción de este artículo, sin embargo, Arabia Saudí ha declarado una guerra al mercado energético mundial, basada en una estrategia marcadamente bajista, que busca contrarrestar a otros productores y mantener a flote la demanda de hidrocarburos saudíes ${ }^{1}$.

b) La divergencia entre realidad y propaganda

La estrategia de modernización capitaneada por MbS reposaba sobre un pilar económico y social, pero también exigía que el resto del mundo fuera consciente de los objetivos y aspectos positivos del plan. Este propósito se perfilaba complicado en vista al interés renovado de la comunidad internacional por los derechos humanos en Oriente Próximo en el periodo post-2011. Conscientes de las contrariedades internas que simboliza Arabia Saudí, las autoridades contrataron a compañías estadounidenses de marketing y comunicación política. Estas diseñaron un plan destinado a que Gobiernos e inversores internacionales apoyaran no solo las reformas, sino también la figura de MbS, hasta aquel momento desconocido y percibido con desconfianza.

Un primer paso fue las publicitadas visitas de MbS a Estados Unidos entre 2017 y 2018, de la mano de anuncios espectaculares sobre avances en la esfera de libertad en el reino. A esto se han ido añadiendo acciones de sports-washing (organización de competiciones deportivas para promocionar la imagen internacional del régimen) y otros instrumentos de softpower, como la contratación de blogueros para promocionar el turismo al país. Este tipo de propaganda es tanto de consumo doméstico como exterior, y se ha mostrado útil a la hora de desviar la atención mediática de la represión en el reino, en particular en lo referido al asesinato del periodista Jamal Khashoggi en el consulado saudí en Turquía y el balance negativo de la guerra en Yemen.

c) MbS y el fin del consenso en la formulación de la política exterior

Las protestas de 2011 y los conflictos posteriores motivaron que la Corona adquiriera un papel cada vez más complejo y expansivo. El principio de liderazgo se encuentra

1. Gregory Brew, «Saudi Arabia's Weaponization of Oil Abundance», Middle East Research and Information Project, 20-3-2020. Disponible en: https://cutt.ly/tmaaah1. 
tensionado por un contexto menos propicio para los intereses del régimen saudí. La preeminencia del poder de Arabia Saudí fue vertebrada durante décadas bajo un espacio de relaciones jerarquizado que situaba al reino como el polo protagonista sobre el resto de los actores regionales. El statu quo imperante hasta la Primavera Árabe era enormemente propicio a los intereses de los príncipes saudíes. El reino ocupaba una posición central en la región. No obstante, las circunstancias actuales limitan la influencia de la casa Saud en el entorno, ya que existen mayores resistencias a su poder.

La llegada al trono de Salman propició nuevas fricciones y divisiones en el seno del clan saudí. Su designación como príncipe heredero (Wolff, 2018) representaba un salto en la línea sucesoria y marginaba al Comité de Lealtad, que era la institución supuestamente encargada de tomar tales decisiones. En una primera fase, el régimen procuró proyectar una sólida imagen de cohesión en la casa Saud. No obstante, bajo el liderazgo de MbS se hacen cada vez más patentes las señales de despatrimonialización extrema del Estado, proceso en virtud del que un importante número de responsabilidades y capacidades decisorias se concentrarían en el círculo de confianza del príncipe heredero, con el fin último de apuntalar su llegada al trono (Mabon, 2018).

La dinámica de concentración del poder ha contribuido a una considerable erosión de prácticas establecidas del Estado saudí relativas al sistema de equilibrios y consenso entre clanes de la familia real (Karim, 2017), lo que aumenta la tensión doméstica que influye en el comportamiento de Arabia Saudí fuera de sus fronteras (Ayoob, 1997). El único contrapeso que el joven dirigente ha mantenido en vigor es la aparición en público de la figura venerada del rey Salman cuando son adoptadas decisiones excesivamente impopulares para la ciudadanía saudí o la comunidad internacional, como el inmovilismo oficial frente a la decisión de Donald Trump de trasladar la embajada estadounidense en Israel o el asesinato de Jamal Khashoggi.

\section{ALIANZAS Y RIVALIDADES EN EL ESCENARIO REGIONAL}

\section{La estrategia de Arabia Saudi para Oriente Próximo}

La presencia de Arabia Saudí en Oriente Próximo se desarrolla en un marco de rivalidad por mayores cotas de poder e influencia, primordialmente focalizado en Irán. Ambos regímenes apelan a narrativas que aluden al islam, pero el antagonismo real radica en la divergencia de intereses: desde la revolución de 1979, los ayatolás proyectan una visión política que apela a la autoridad y poder iraní en el entorno (Al-Rasheed y Abdolmohammadi, 2018: 5-6), lo que directamente perturba las pretensiones de la casa Saud, que considera el liderazgo regional como pilar central de su supervivencia.

El Plan de Acción Integral Conjunto (JCPoA, siglas en inglés) suscrito en julio de 2015 por Irán con EE. UU., China, Rusia, Alemania, Francia, Reino Unido y la Unión Europea, permitió a Teherán recobrar cierto reconocimiento internacional. La estrategia del presidente Barack Obama generó una crisis sustancial con Riad, quienes estimaron esta decisión como una falta de compromiso con sus aliados árabes. Las 
relaciones volvieron a mejorar con Donald Trump, quien compartió la visión beligerante de Arabia Saudí o Israel sobre Irán (Parsi, 2017: 377-379). La crisis en el estrecho de Ormuz en 2019, junto al asesinato del general iraní Qasem Sulemani en enero de 2020, remarca un repunte de la escalada de tensión contra el Estado iraní en la zona.

La rivalidad creciente entre Irán y Arabia Saudí encuentra otro vector principal en los acontecimientos tras la Primavera Árabe. El régimen iraní aprovechó las circunstancias para ampliar su influencia, consolidada a través de alianzas con actores estatales y no estatales en distintos países (Kausch, 2017: 38-39). Los saudíes se enfrentan a una fuerza en ascenso que aspira a superarles como potencia regional. La rivalidad todavía no se traduce en una confrontación militar directa, ni parece que sea la voluntad real de ningún de los dirigentes por el momento. Las posiciones contrapuestas, empero, impiden retomar niveles mínimos de estabilidad en Oriente Próximo.

Las diferencias entre Irán y Arabia Saudí se trasladan a otros contextos de enfrentamiento, entre los que destaca la crisis emergida en el seno del CCG como consecuencia de disonancias entre las familias reales de los Saud y los Al Thani. Estas desavenencias devienen del periodo anterior a las revueltas árabes de 2011. Desde Doha se comenzó a articular, a mediados de la década de los noventa, una política exterior ambiciosa caracterizada por una agenda propia que prescindía abiertamente de la tutela saudí (Ulrichsen, 2014: 68-70). Catar pretende implementar una estrategia separada de las grandes líneas marcadas por Arabia Saudí, que siempre ha considerado al resto de miembros del Consejo como partes intrínsecas de su zona natural de influencia.

Los incidentes de los últimos años ponen de manifiesto las disimilitudes entre los miembros de la organización regional y, sobre todo, las divergencias entre cataríes y saudíes. La falta de complementariedad entre las estrategias de cada Estado se ha traducido en objetivos distintos, incluso contrarios, en espacios como Egipto, Siria o Yemen. El bloqueo económico y político impuesto por el llamado Cuarteto Árabe liderado por Arabia Saudí desde 2017 contra el emirato catarí representa una brecha excepcional en el otrora eje de monarquías árabes (Naheem, 2017: 266-267).

Catar no parece dispuesta a renunciar a ninguno de sus intereses nacionales, ni a ceder parte de su soberanía. La acción catarí se presenta como alternativa a los espacios polarizantes que Arabia Saudí e Irán pretenden constituir. Doha intenta destacar en una coyuntura regional marcada por la volatilidad de las alianzas líquidas, en las que se conforman bloques no por un objetivo común, sino por las percepciones compartidas de una misma amenaza (Soler i Lecha, 2017), que varían según las circunstancias. Catar aspirara a establecer redes de interdependencia flexibles, que le permitan ampliar sus espacios de influencia y preservar sus intereses de forma independiente.

La acción saudí tiene corolarios en otros lugares de Oriente Próximo, utilizando terceros actores o proxy actor, facciones políticas o religiosas financiadas y apoyadas por Arabia Saudí (Marshall, 2016: 183-185). Este tipo de maniobra fue implementada en Siria. Bashar Al Asad es un estrecho aliado de Irán, motivo principal por el que potencias como Arabia Saudí, Turquía o EAU intentaron transformar la guerra en una disputa global. Los príncipes saudíes apoyaron a las principales facciones de la 
oposición (Álvarez-Ossorio, 2015: 169-170), pero la falta de entendimiento con el resto de las potencias generó un desequilibrio en la contienda. Con el respaldado de rusos e iraníes, el régimen sirio ha logrado recuperar gran parte del control territorial.

Las inferencias saudíes también son reseñables en países como Líbano o Irak. En el caso libanés, Arabia Saudí persiste en apoyar a los partidos de carácter suní para contrarrestar la fuerte presencia chií. No obstante, esta carencia sectaria se ha visto superada por las multitudinarias protestas de 2019, lo que precipitó la caída del Gobierno de Saad Hariri y erosionó la imagen de las formaciones tradicionales. En la misma línea, la arena política iraquí se ha convertido en foco de disputa entre potencias. El régimen saudí ha estrechado vínculos no solo con facciones suníes iraquíes, sino también con el Gobierno Regional del Kurdistán (KRG), con el propósito de intentar condicionar las dinámicas internas del país y buscar aliados sobre el terreno.

El militarismo en las acciones regionales se ha convertido en otro elemento central de la estrategia de Arabia Saudí para Oriente Próximo. El rey Abdalá estableció un precedente securitario al acudir en asistencia de la familia Al Jalifa en Bahréin en 2011, amparándose en la aplicación del Escudo de la Península del CCG (Matthiesen, 2013: 50-53). No obstante, el gran paso se da en Yemen en 2015 con la Operación Tormenta Decisiva lanzada por la coalición liderada por Arabia Saudí, que cuenta con el respaldo de sus principales aliados regionales. Esta intervención representó la primera vez que los saudíes establecían una campaña militar tan prolongada en otro país.

Las resistencias al liderazgo saudí son más diversas que antes de 2011, motivos por los que el reino se habría visto obligado a renunciar a un posicionamiento absoluto y a centrarse en la constitución de un eje suní que le permita seguir erigiéndose en referente frente a bloques que considera díscolos y revolucionarios. Riad buscaría extender la aplicación del axioma primus inter pares (Ehteshami, 2012: 264-265) no únicamente en el seno del CCG, sino en todo un conjunto de socios de Oriente Próximo, Magreb y demás zonas de tradición musulmana. Una coalición que tenga como centro Arabia Saudí y como aglutinador el antagonismo hacia otras potencias. La síntesis de la estrategia regional radicaría, por tanto, en contener el deterioro de las posiciones saudíes y, para ello, restituir un frente bajo el liderazgo de Riad, que garantice suficiente estabilidad y legitimidad al clan familiar dentro y fuera del reino.

\section{Condicionantes internos para la nueva estrategia regional}

a) Un nuevo nacionalismo saudí

La creación del Estado moderno saudí se llevó a cabo «sin una memoria histórica de unidad o patrimonio nacional» (Al-Rasheed, 2010: 3). El régimen se constituyó sobre la base de legitimidad de la dinastía, el wahabismo y poderosas alianzas con tribus locales. En Estados del Golfo como Arabia Saudí ha predominado estos últimos ańos un nuevo componente definido como nacionalismo militarizado (Ardemagni, 2019), que cuenta entre sus objetivos consolidar el proceso de construcción del Estado 
y limitar conflictos domésticos (Ayoob, 1998). La Corona saudí intenta promocionar una identidad nacional homogénea, sirviéndose de mecanismos de diplomacia pública y soft power, o incluso de ingeniería social. Así, por ejemplo, se ha puesto énfasis en permitir que sea estudiada la historia preislámica del territorio, lo que constituye una decisión sin precedentes.

La estrategia saudí de diversificación económica cuenta entre sus fines dar forma a una nueva ciudadanía nacional. MbS es consciente de la importancia de forjar vínculos de pertenencia más fuertes en torno a un nuevo pacto social. De acuerdo con la nueva narrativa, los ciudadanos tendrán a su disposición nuevas formas de prosperar, tanto en el ámbito económico, gracias a la saudización del empleo y la puesta en marcha de planes para el emprendimiento y potenciación del sector privado, como en el ámbito social con medidas que multiplican sus posibilidades de entretenimiento. Esta narrativa habría contribuido al aumento de popularidad -incluso culto a la personalidad- del príncipe heredero, que aspira a representar a la nueva generación de saudíes.

Numerosos instrumentos de propaganda han sido desplegados para convencer a los saudíes de las bondades de la estrategia de modernización del reino, tanto en lo que respecta a demandas locales frente a la corrupción o la desigualdad como a acciones en la región (Al-Rasheed, 2018: 3). El régimen potencia la creencia de que la corona está destinada a desempeñar un papel de liderazgo regional, presentando como un éxito las acciones llevadas a cabo en el entorno. Dentro de la dinámica de combinación de nacionalismo y sectarismo, un creciente número de saudíes apoyarían en este sentido la intervención en Yemen, convencidos de la amenaza sectaria (presentada como "expansión safaví») impulsada por la República Islámica de Irán, aún más peligrosa si se tiene en cuenta que tiene lugar en el patio trasero de Arabia Saudí (Al-Rasheed, 2015b: 19).

La marcada militarización de la acción exterior, con el ejemplo destacado de Yemen, es acompañada de un mayor militarismo interno, a pesar de que el Ejército era una institución menor en Arabia Saudí. Se intenta trasladar a la sociedad saudí que su estabilidad no puede depender de ningún aliado externo, sino únicamente de la Corona (Gaub, 2016: 1). Esta militarización es, además, reflejo de la mayor concentración de poder de MbS, quien en un esfuerzo por consolidar su Gobierno ha realizado una profunda reestructuración de las agencias de seguridad (Ardemagni, 2019).

b) La sectarización de la política nacional saudí

A partir de 2011, el Gobierno saudí describió el islam como «el factor más importante que afecta a la determinación de las prioridades de la política exterior del Reino» (Saudi Arabian Ministry of Foreign Affairs, 2011). El régimen saudí recurrió a su identidad islámica con ocasión de los levantamientos antiautoritarios, intensificando su relación con los países musulmanes suníes, a los que invitó a poner en marcha, por ejemplo, ejercicios militares conjuntos. Estas iniciativas tenían como objetivo reforzar los vínculos entre regímenes y plantear una especie de cordón sanitario contra Irán. 
Riad comenzó a poner en obra la narrativa de sectarización que había resultado productiva en referencia a su población chií en la Provincia Oriental, y que también revivieron tras 2011 (Al-Rasheed, 2017), en un nuevo ejemplo de política exterior dictada tanto por los aspectos domésticos como por los condicionantes externos (Ayoob, 2002).

La instrumentalización política de las divisiones sectarias se ha convertido en dinámica habitual en Oriente Próximo y, en menor medida, el norte de África. Los respectivos regímenes desestiman las demandas de sus poblaciones y alegan la necesidad de un autoritarismo paternalista que proteja a los ciudadanos de amenazas externas que, en ocasiones, también afectan a la arena doméstica. Gengler habla de «economía política del sectarismo», con un énfasis particular en el Golfo, en atención a los incentivos que encuentran los respectivos monarcas en la explotación de tensiones sectarias para cultivar fuentes de legitimidad no económicas y garantizar suficiente apoyo al régimen (Gengler, 2017). Estos gobernantes habían basado su legitimidad durante décadas en la pertenencia a un particular clan y no a una determinada secta, pero utilizaron una narrativa simplista y útil en la clasificación de seres humanos como pertenecientes a «unidades primordiales y eternas», tanto de cara a parte de sus ciudadanos como de la comunidad internacional (Al-Rasheed, 2017: 155-156). De esta forma, el sentimiento de adscripción identitaria diseńado tiene el objetivo de «homogeneizar [...] sujetos y moldearlos en una única entidad" (Al-Rasheed, 2015c).

El conflicto intrasunní con Catar —el único país que también sigue la tradición wahabita en la región - ofrece evidencias de que Arabia Saudí hace un uso selectivo de la estrategia de sectarización (Lynch, 2017). La instrumentalización de la pertenencia sectaria parece condenar a los regímenes involucrados a sostener, y en ocasiones profundizar, su participación en conflictos regionales. Así lo demuestra el avivamiento por parte de Arabia Saudí del conflicto — discursivo, pero también corpóreo- por delegación con Irán en el marco de la llamada Guerra Fría de Oriente Próximo. Uno de los daños colaterales más evidentes de la estrategia de sectarización parece haber sido la consolidación de rivalidades en la península arábiga, erosionando así una identidad jaliyi (en árabe, natural del Golfo) cultivada durante años (Ardemagni, 2019).

\section{c) «Regionalismo regime-boosting»}

La estrategia de Arabia Saudí también representa un ejemplo destacado de «regionalismo regime-boosting». La definición es aplicable a la continuidad de organizaciones deterioradas como la Liga Árabe, la Organización para la Cooperación Islámica y el Consejo de Cooperación del Golfo. Todas ellas se han convertido en medios para reforzar la postura de Arabia Saudí en la región y ante la comunidad internacional. La presidencia saudí del G20 en noviembre de 2020 también se perfiló como ejemplo de esta estrategia desde un punto de vista propagandística, en contraposición a la adopción de decisiones significativas en el seno del foro económico.

En 2020 se daba forma a un nuevo caso de regionalismo utilitarista para reforzar la legitimidad y estabilidad del régimen saudí: es el caso del Consejo del Mar Rojo y el 
Golfo de Adén, cuyo objetivo declarado principal consiste en mejorar la cooperación política, económica y de seguridad entre sus miembros ${ }^{2}$ en torno a una zona de creciente competencia entre potencias regionales como son el mar Rojo y el Cuerno de África. La organización cuenta como miembros a Egipto, Jordania, Eritrea, Yemen, Sudán, Djibouti y Somalia. La configuración inicial de la organización fue inicialmente perfilada para centrarse en una serie de temas como la cooperación económica, los intercambios culturales y los problemas ambientales, pero bajo el liderazgo de Arabia Saudí ha centrado su atención en los problemas de seguridad.

\section{CONCLUSIONES}

Este artículo ha intentado demostrar que la política exterior de Arabia Saudí es resultado tanto de los acontecimientos regionales e internacionales como de las circunstancias internas del país. La estrategia exterior de Arabia Saudí responde a la necesidad de supervivencia y estabilidad de la Corona y, por tanto, a las percepciones que esta tiene de las amenazas a su legitimidad. Su papel de referente regional se erigió durante años como garantía de estabilidad y seguridad. El texto reconoce que las revueltas antiautoritarias de 2011 representaron un punto de inflexión para la casa Saud, que había conseguido moldear un orden regional con el que se sentía cómodo, lo que la condujo a reconstituir sus acciones dentro y fuera del reino.

El principal reto para la dinastía Saud sigue consistiendo en preservar la naturaleza autoritaria y neopatrimonial del régimen frente a unos escenarios doméstico y exteriores caracterizados por la incertidumbre. Las estrechas vinculaciones entre los dos niveles determinan las percepciones de amenaza y oportunidad de los dirigentes saudíes. La irrupción de la figura de MbS no representa un elemento coyuntural o accidental, puesto que su ascenso al poder y la forma de ejercerlo representan una nueva fase evolutiva del reino. El príncipe heredero intenta reconfigurar ciertos pilares del sistema, la política de seguridad e internacional, en lo que él mismo denomina "cuarto Estado saudí», aunque en muchas ocasiones, como es el caso de la economía política, ha recuperado dinámicas que en el pasado garantizaron la consolidación del régimen, fiel a un cierto gatopardismo: "Cambiar todo para que nada cambie».

Las transformaciones en el contexto regional obligan a Arabia Saudí a ir más allá de la mera gestión del orden preestablecido y, por tanto, a adoptar posturas abiertamente proactivas. Las presiones internas y externas parecen inducir a que la Corona saudí tenga que replantear algunas de sus premisas más elementales para asegurar su liderazgo en el entorno y la naturaleza política de su régimen. Las acciones emprendidas por MbS se centran en reconstruir espacios de preponderancia en Oriente Próximo, utilizando recurrentemente el argumento sectario de la identidad árabe y

2. Abdel Aziz Aluwaisheg, 2020. "Council of Red Sea and Gulf of Aden to play critical role», Arab News, 13-1-2020. Disponible en: https://www.arabnews.com/node/1612471. 
suní en contraposición a otros ejes políticos. Esta estrategia le lleva a revitalizar un tipo de nacionalismo vinculado a una perspectiva militarista en el orden interno, al mismo tiempo que introduce progresivas reformas en el país, aunque sin alterar el statu quo prevaleciente. Estas respuestas pueden resultar insuficientes para sus intereses si la correlación de fuerzas a escala regional se mantiene propensa a cambios más profundos.

Una de las características del marco teórico del realismo subalterno consiste en que los regímenes implementan cambios en su política exterior que podrían ser beneficiosos para su posición en el corto plazo, sin por ello ser ventajosos en el largo plazo (Ayoob, 1997, 1998, 2002). La prioridad absoluta la representa la consolidación del proceso de construcción de Estado y, como elemento central, la legitimidad del régimen y élite a cargo de este. El artículo presenta algunos de estos supuestos en el caso de Arabia Saudí, como por ejemplo la guerra de Yemen o el bloqueo a Catar. Además, permite entender algunas decisiones recientes que apuntarían a una cierta reflexividad y menor agresividad de Riad, confrontada con la posibilidad de que estallara otro conflicto en el vecindario. La evolución de los acontecimientos dirá si se trata de un cambio total de estrategia o una modificación estrictamente coyuntural.

\section{Referencias}

Ahmadian, Hassan. 2018. "Iran and Saudi Arabia in the Age of Trump", Survival. Global Politics and Strategy, 60 (2): 133-150. Disponible en: https://doi.org/10.1 080/00396338.2018.1448579.

Ahrari, Mohammed E. 1989. The Gulf and International Security: The 1980s and beyond. Londres: Palgrave. Disponible en: https://doi.org/10.1007/978-1-349-10864-0.

Alamer, Sultan (ed.). 2016. Fi tarikh al-Uruba. Beirut: Jusour.

Al-Kibsi, Gassan, Jonathan Woetzel, Tom Isherwood, Jawad Khan, Jan Mischke y Hassan Noura. 2015. Saudi Arabia beyond Oil: The Investment and Productivity Transformation. Londres; Dubai: McKinsey Global Institute. Disponible en: https://cutt.ly/LmaP0Go.

Al-Rasheed, Madawi. 2010. A History of Saudi Arabia. Londres: Cambridge University Press. Disponible en: https://doi.org/10.1017/CBO9780511993510.

Al-Rasheed, Madawi. 2014. «Saudi Internal Dilemmas and Regional Responses to the Arab Uprisings", en Fawaz Gerges (ed.), The New Middle East. Protest and Revolution in the Arab World. Londres: Cambridge: Cambridge University Press.

Al-Rasheed, Madawi. 2015a. Muted Modernists. The Struggle Over Divine Politics in Saudi Arabia. Oxford: Oxford University Press.

Al-Rasheed, Madawi. 2015b. Is It Always Good to Be King? Saudi Regime Resilience After the 2011 Arab Popular Uprisings. London School of Economics Middle East Centre Papers, 12. Disponible en web: http://eprints.lse.ac.uk/64749/.

Al-Rasheed, Madawi. 2015c. "How united is the GCC?», Al-Monitor, 3-4-2015. Disponible en: https://cutt.ly/WmaAdEJ. 
Al-Rasheed, Madawi. 2017. «Sectarianism as Counter-Revolution: Saudi Responses to the Arab Spring», en Nader Hashemi y Danny Postel (eds.), Sectarianization. Mapping the New Politics of the Middle East. Oxford: Oxford University Press.

Al-Rasheed, Madawi (ed.). 2018. Salman»s Legacy. The Dilemmas of a New Era in Saudi Arabia. Oxford: Oxford University Press.

Al-Rasheed, Madawi y Pejman Abdolmohammadi. 2018. Saudi Arabia and Iran: Beyond Conflict and Coexistence? Workshop Proceedings. LSE Middle East Centre Report. Agosto de 2018. Disponible en: https://cutt.ly/0maAGHv.

Al Tamamy, Saud Mousaed. 2012. "Saudi Arabia and the Arab Spring: opportunities and challenges security", Journal of Arabian Studies: Arabia, the Gulf, and the Red Sea, 2 (2): 143-156. Disponible en: https://doi.org/10.1080/21534764.20 12.734117 .

Álvarez-Ossorio, Ignacio. 2015. «El enroque autoritario del régimen sirio: de la revuelta popular a la guerra civil», Revista CIDOB d'Afers Internacionals, 109: 157-176.

Ardemagni, Eleonora. 2019. Gulf Monarchies' Militarized Nationalism. Carnegie Endowment for International Peace. Disponible en: https://carnegieendowment. org/sada/78472.

Ayoob, Mohammed. 1997. «Defining Security: A Subaltern Realist Perspective», en Keith Krause y Michael C. Williams (eds.), Critical Security Studies: Concepts and Cases. Minneapolis: University of Minnesota Press.

Ayoob, Mohammed. 1998. «Subaltern Realism: International Relations Meets the Third World", en Stepahnie Neuman (ed.), International Relations Theories and the Third World. Nueva York: St. Martin's Press.

Ayoob, Mohammed. 2002. "Inequality and Theorizing in International Relations: The Case for Subaltern Realism», International Studies Review, 4 (3): 27-48. Disponible en: https://doi.org/10.1111/1521-9488.00263.

Azaola, Bárbara. 2019. "The foreign policy of post-Mubarak Egypt and the strengthening of relations with Saudi Arabia: Balancing between economic vulnerability and regional and regime security", The Journal of North African Studies, 24 (3): 401-425. Disponible en: https://doi.org/10.1080/13629387.2018.145 4650 .

Bach, Daniel. 2011. "Patrimonialism and neopatrimonialism: Comparative trajectories and readings", Commonwealth and Comparative Politics, 49 (3): 275-294. Disponible en: https://doi.org/10.1080/14662043.2011.582731.

Bank, André y Thomas Ritcher. 2010. «Neopatrimonialism in the Middle East and North Africa: Overwiew, critique and alternative conceptualization». Conference: Workshop Neopatrimonialism in Various World Regions, at the GIGA German Institute of Global and Area Studies, Hamburg.

Baumann, Hannes. 2019. "The transformation of Saudi Arabia»s rentier state and "the international"», Globalizations, 16 (7): 1165-1183. Disponible en: https:// doi.org/10.1080/14747731.2019.1573870.

Beblawi, Hazem. 1990. "The rentier state in the Arab world», en Giacomo Luciani (ed.), The Arab state. Berkeley: University of California Press. 
Buzan, Barry y Ole Waever. 2003. Regions and Powers: The Structure of International Security. Cambridge: Cambridge University Press. Disponible en: https://doi. org/10.1017/CBO9780511491252.

Campbell, Evan y Steve A. Yetiv 2017. «Realpolitik and Religion: The Twin Sources of Saudi Arabia's Foreign Policy", en Jack Covarrubias (ed.). Strategic Interests in the Middle East. Opposition or Support for US Foreign Policy. Londres: Routledge.

Chabal, Patrick y Jean Pascal Daloz. 1999. Africa Works: Disorder as Political Instrument. Oxford: James Currey.

Charrad, Mounira. M. 2011. "Central and local patrimonialism: state-building in Kin-based societies». The Annals of the American Academy of Political and Social Science, 636: 49-68. Disponible en: https://doi.org/10.1177/0002716211401825.

Chalk, Peter. 2004. "Non-Military Security in the Wider Middle East", Studies in Conflict and Terrorism, 26: 197-214. Disponible en: https://doi.org/10.1080/ 10576100390211428.

Dalacoura, Katerina. 2012. "The 2011 uprisings in the Arab Middle East: Political change and geopolitical implications», International Affairs, 88 (1): 63-79. Disponible en: https://doi.org/10.1111/j.1468-2346.2012.01057.x.

Ehteshami, Anoushiravan. 2012. "Security and strategic trends in the Middle East», en David Held y Kristian Coates Ulrichsen (eds.), The transformation of the Gulf. Politics, economics and the global order. Londres: Routledge, Taylor and Francis Group.

Gallarotti, Giulio y Isam Y. Al-Filali. 2012. «Saudi Arabia’s soft power», International Studies, 49:233-261.Disponibleen: https://doi.org/10.1177/0020881714532707. Gater-Smith, Philp. 2018. «Complex interdependence in the China-Saudi-US triangle. Assesing shifts in the issue area linkages between energy trade and security ties», en Anoushiravan Ehteshami y Niv Horesh (eds.), China's presence in the Middle East. The implications of the one belt, one road initiative. Nueva York: Routledge, Taylor and Francis Group. Disponible en: https://doi.org/10.4324/9781315185736-7.

Gaub, Florence. 2016. «Saudi Arabia and the Islamic Alliance», EUISS Brief, 5-2-2016. Disponible en: https://cutt.ly/UmaDhXG.

Gause, F. Gregory. 2003. «Balancing What? Threat Perception and Alliance Choice in the Gulf", Security Studies, 13 (2): 273-305. Disponible en: https://doi. org/10.1080/09636410490521271.

Gause, F. Gregory. 2011. "Is Saudi Arabia really counter-revolutionary?», en The Saudi Counter-Revolution. Arab uprisings. POMEPS Briefings, 5. Disponible en: https://cutt.ly/hmaDJvX.

Gengler, Justin. 2017. «The Political economy of Sectarianism: How Gulf Regimes exploit identity Politics as a Survival Strategy», en Frederic Wehrey (ed.). Beyond Sunni and Shia. The Roots of Sectarianism in a Changing Middle East. Oxford: Oxford University Press. Disponible en: https://doi.org/10.1093/oso/978019087 6050.003.0009.

Halliday, Fred. 2005. The Middle East in International Relations: Power, Politics and Ideology. Cambridge: Cambridge University Press. Disponible en: https://doi. org/10.1017/CBO9780511790829. 
Hammond, Andrew. 2018. «Producing Salafism: From Invented Tradition to State Agitprop», en Madawi Al-Rasheed (ed.), Salman»s Legacy. The Dilemmas of a New Era in Saudi Arabia. Oxford: Oxford University Press.

Hanieh, Adam. 2011. Captalism and Class in the Gulf Arab States. Palgrave McMillan. Disponible en: https://doi.org/10.1057/9780230119604.

Hinnebusch, Raymond A. 2003. The International Politics of the Middle East. Manchester: Manchester University Press.

Jayamaha, Buddhika, Kevin S. Petit, Jahara Matisek, William Reno, Matthew A. Rose y Molly Jahn. 2019. "The Great Saudi-Iranian proxy game», Middle East Quarterly, 26 (4): 1-10.

Kamrava, Mehran. 2011. The Arab Spring and the Saudi-Led Counterrevolution. Foreign Policy Research Institute. Disponible en: https://doi.org/10.1016/j. orbis.2012.10.010.

Kamrava, Mehran. 2013. Mediation and Saudi Foreign Policy. Foreign Policy Research Institute. Disponible en: https://cutt.ly/xmaFoDK.

Karim, Umer. 2017. "The Evolution of Saudi Foreign Policy and the Role of Decision-making Processes and Actors", The International Spectator, 52 (2): 71-88. Disponible en: https://doi.org/10.1080/03932729.2017.1308643.

Kausch, Kristina. 2017. "State and non-state alliances in the Middle East», The International Spectator, 52 (3): 36-47. Disponible en: https://doi.org/10.1080/039327 29.2017.1347250.

Krieg, Andreas. 2016. «Externalizing the burden of war: the Obama Doctrine and US foreign policy in the Middle East», International Affairs, 92 (1): 97-113. Disponible en: https://doi.org/10.1111/1468-2346.12506.

Lynch, Mark. (ed.). 2017. "The Qatar Crisis», POMEPS Briefings, 31-10-2017. Disponible en: https://cutt.ly/FmaFxhe.

Mabon, Simon. 2016. Saudi Arabia and Iran. Power and rivalry in the Middle East. Londres: I. B. Tauris.

Mabon, Simon. 2018. "It's a family affair: Religion, geopolitics and the rise of Mohammed bin Salman», Insight Turkey, 20 (2): 51-66. Disponible en: https:// doi.org/10.25253/99.2018202.04.

Marshall, Alex. 2016. "From civil war to proxy war: past history and current dilemmas», Small Wars and Insurgencies, 27 (2): 183-195. Disponible en: https://doi.org/10.1 080/09592318.2015.1129172.

Matthiesen, Toby. 2012. "A "Saudi Spring"?: The Shi'a Protest Movement in the Eastern Province 2011-2012», Middle East Journal, 66 (4): 628-659. Disponible en: https://doi.org/10.3751/66.4.14.

Matthiesen, Toby. 2013. Sectarian Gulf. Bahrain, Saudi Arabia, and the Arab Spring that wasn't. Stanford Briefs. Stanford. Disponible en: https://doi.org/10.1017/ CBO9781107337732.

Matthiesen, Toby. 2014. The Other Saudis: Shiism, Dissent, and Sectarianism. Cambridge: Cambridge University Press. Disponible en: https://doi.org/10.1017/ CBO9781107337732. 
Médard, Jean Francois. 1990. "L'État patrimonialisé», Politique africaine, 39: 25-36.

Mouline, Nabil. 2010. «Power and Generational Transition in Saudi Arabia», Critique Internationale, 46. Disponible en: https://doi.org/10.3917/crii.046.0125.

Naheem, Mohammed Ahmad. 2017. "The dramatic rift and crisis between Qatar and the Gulf Cooperation Council (GCC) of June 2017», International Journal of Disclosure and Governance, 14 (4): 265-277. Disponible en: https://doi.org/ 10.1057/s41310-017-0025-8.

Nonneman, Gerd. 2005. "Determinants and Patterns of Saudi Foreign Policy: "Omnibalancing" and "Relative Autonomy" in Multiple Environments", en Paul Aarts y Gerd Nonneman (eds.), Saudi Arabia in the Balance: Political Economy, Society, Foreign Affair. Londres: Hurst and Company.

Nuruzzaman, Mohammed. 2017. "Conflicts in Sunni Political Islam and Their Implications», Strategic Analysis, 41(3): 285-296. Disponible en: https://doi.org/10.10 80/09700161.2017.1295612.

Nuruzzaman, Mohammed. 2019. "Chasing the dream: the Salman Doctrine and Saudi Arabia's bid for regional dominance», Insight Turkey, 21 (3): 41-51. Disponible en: https://doi.org/10.1057/S41310-017-0025-8.

Ottaway, David. 2011. Saudi Arabia in the Shadow of the Arab revolt. Occasional Paper Series. Summer 2011. Middle East Program. Woodrow Wilson International Center for Scholars. Disponible en: https://cutt.ly/8maGqe9.

Parsi, Trita. 2017. Losing an enemy. Obama, Iran, and the triumph of diplomacy. Londres: Yale University Press.

Saudi Arabian Ministry of Foreign Affairs. 2011. "The Foreign Policy of the Kingdom of Saudi Arabia». Disponible en: https://cutt.ly/xmaGyOv.

Söderbaum, Fredrik. 2001. "African Regionalism and EU-African Interregionalism", en M. Telò (ed.), European Union and New Regionalism. Regional Actors and Global Governance in a Post-Hegemonic Era. Farham: Ashgate.

Söderbaum, Fredrik. 2010. «With a Little Help from My Friends: How Regional Organizations in Africa Sustain Clientelism, Corruption and Discrimination». Paper, Political Science Association's Annual Meeting, Gothenburg, 30 de septiembre-2 de octubre, 2010.

Soler i Lecha, Eduard. 2017. "Alianzas líquidas en Oriente Medio». Anuario International $C I D O B, 2016$ : 148-155. Disponible en: https://cutt.ly/qmaHy0q.

Steinberg, Guido. 2014. Leading the counter-revolution: Saudi Arabia and the Arab Spring. SWP Research Paper. Disponible en: https://cutt.ly/FmaHlc7.

Ulrichsen, Khristian Coates. 2014. Qatar and the Arab Spring. Londres: Oxford University Press.

Wolff, Michael. 2018. Fire and Fury: Inside the Trump White House. Londres: Little Brown.

Yom, Sean L. y F. Gregory Gause. 2012. «Resilient royals: how Arab monarchies hang on", Journal of Democracy, 23 (4): 74-88. Disponible en: https://doi.org/10.1353/ jod.2012.0062. 
Presentado para evaluación: 20 de octubre de 2020.

Aceptado para publicación: 27 de mayo de 2021.

\section{ITXASO DOMÍNGUEZ DE OLAZÁBAL}

dominguez.itxaso@gmail.com

Coordinadora del Panel de Oriente Próximo y Norte de África de la Fundación Alternativas y profesora asociada de Estudios Internacionales en la Universidad Carlos III de Madrid. Es doctora en Estudios Árabes e Islámicos por la Universidad Autónoma de Madrid e investigadora del TEIM (Taller de Estudios Internacionales Mediterráneos) de la misma universidad, así como del Grupo para el Estudio de las Sociedades Árabes y Musulmanas (GRESAM) de la Universidad de Castilla-La Mancha. Sus principales áreas de especialidad son, desde una perspectiva de estudios críticos, las relaciones de poder pasadas y presentes en la Palestina histórica, las dinámicas en el golfo Pérsico y los procesos de transición y transformación en Oriente Próximo y el norte de África.

\section{DAVID HERNÁNDEZ MARTÍNEZ}

david.hernandez@inv.uam.es

Miembro del Taller de Estudios Internacionales Mediterráneos (Universidad Autonóma de Madrid). Profesor en Cooperación Internacional y Relaciones Internacionales en la Universidad Camilo José Cela. Colaborador honorífico del Departamento de Relaciones Internacionales e Historia Global (Universidad Complutense de Madrid). Doctor en Relaciones Internacionales por la Universidad Complutense de Madrid. Miembro del grupo de investigación Seguridad, Desarrollo y Comunicación en la Sociedad Internacional (Universidad Complutense de Madrid). Sus principales áreas de especialidad son las dinámicas regionales en el golfo Pérsico, política y sociedad en Oriente Próximo y el norte de África, política exterior de España hacia el mundo árabe y política de vecindad de la Unión Europea. 